Submission ID: 43895

\title{
Using 3D Seismic Data on R. Trebs Field for Reducing Risks During Drilling of
} New Wells

E.A. Valeeva* (BashNIPIneft LLC)

\section{SUMMARY}

The considered approach of seismic data interpretation at the R.Trebs field is used to determine all new wells location. Statistical evaluation of drilling results shows its high efficiency, in spite of the extreme simplicity and the inability of a quantitative forecast of capacities. 


\section{Использование данных сейсморазведки МОГТ-ЗД на месторождении им. Р. Требса для снятия рисков при бурении новых скважин}

\section{Э.А. Валеева* (ООО «БашНИПИнефть»)}

\section{Введение}

Месторождение им. Р.Требса расположено в северно-восточной части Хорейверской впадины на севере Тимано-Печорской нефтегазоносной провинции. Открыто в 1987 г. Приурочено к моноклинали, погружающейся в северо-восточном направлении, осложненной локальными структурами, а также серией разломов субмеридионального простирания.

Наряду с карбонатами верхнего девона и пачкой D3dm доманикового горизонта промышленно-нефтеносными в разрезе месторождения являются нижнедевонские отложения, выделяемые в объеме локховского яруса. Разрез яруса представлен двумя циклами, отвечающими овинпармскому и сотчемкыртынскому горизонтам. На западе месторождения нижнедевонские отложения выклиниваются по типу эрозионного срезания на наиболее приподнятых участках. Рельеф эрозионной поверхности нижнего девона, по мере размыва отложений пачек локховского яруса, в направлении с запада на восток отображает рельеф кровли той или иной пачки, соответственно.

Методы и пути решения. До 2014 года при интерпретации данных сейсморазведки использовалось разделение овинпармских отложений на две пачки: нижнюю - терригеннокарбонатную (D $\left.\mathrm{D}_{1} \mathrm{p} \_\mathrm{a}\right)$ и верхнюю - карбонатную ( $\mathrm{D}_{1} \mathrm{op} \_$б). Проводилась корреляция следующих отражающих горизонтов: от кровли размытой поверхности разновозрастных карбонатно-терригенных отложений лохковского яруса $\left(\mathrm{O \Gamma} \mathrm{IIID}_{1}\right)$; от кровли отложений пачки «б» овинпармского горизонта нижнего девона, вмещающих в себя залежь $\mathrm{D}_{1}$-II $(\mathrm{O \Gamma}$ IIID') и от кровли пачки «а» овинпармского горизонта нижнего девона, в отложениях которой была установлена залежь $\mathrm{D}_{1}-\mathrm{I}\left(\mathrm{O \Gamma} \mathrm{IIID}_{1} "\right)$ (рис. 1).

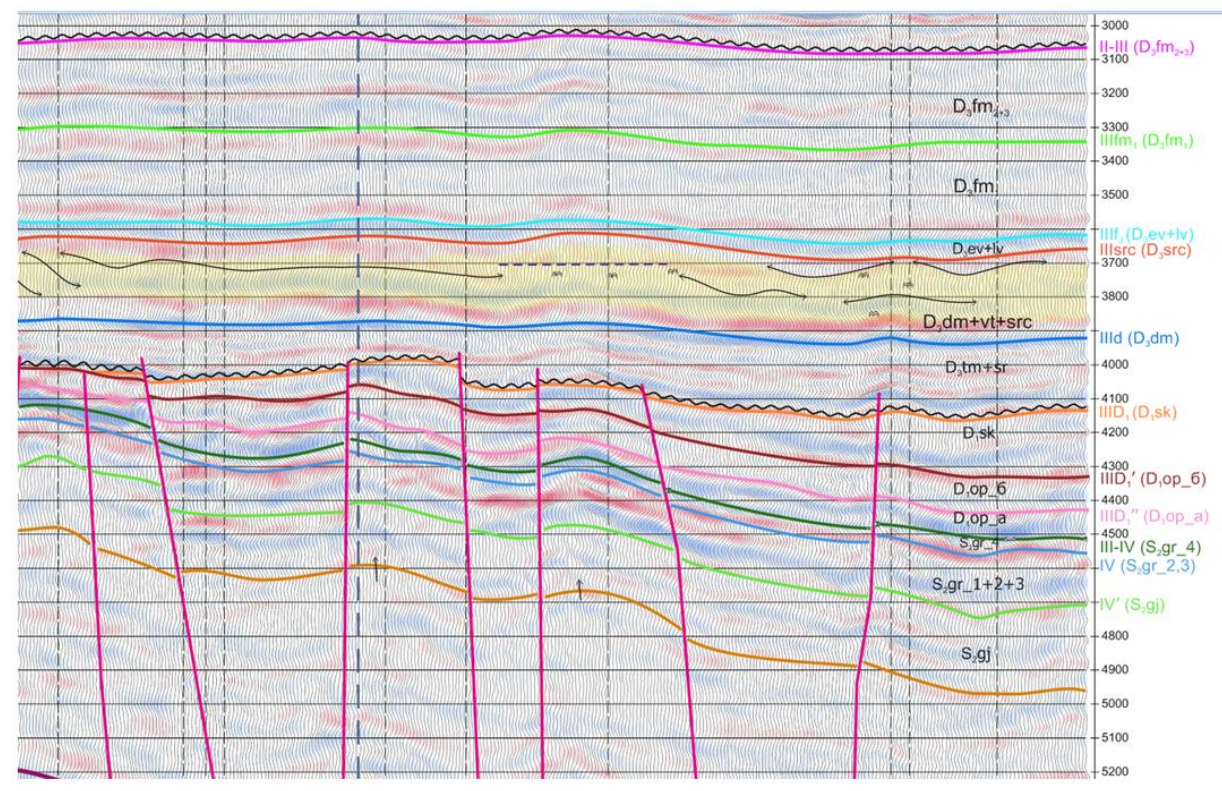

Рисунок 1 Сейсмогеологический разрез по профилю 2Д. Пример стратиграфической разбивки отражающих горизонтов прошлых лет (интерпретащия ОАО «НМСР», для АНК «Бамнефть», 2012 г.).

Время показало, что подобное деление не позволяет с достаточной точностью определять зоны, наиболее благоприятные для бурения как поисковых, так и эксплуатационных скважин. 
В 2013-2015 годах в пределах месторождения им. Р.Требса были проведены сейсморазведочные работы модификации МОГТ-ЗД. В результате обработки (компания «ПетроТрейс») получен сейсмический куб высокого качества, амплитудные и частотные характеристики которого дали возможность проводить интерпретацию с гораздо более высокой детальностью, чем ранее. В то же самое время специалистами ООО «БашнНИПИнефть» было проведено более дробное разделение подсчетных объектов овинпармских отложений и идентификация приуроченных к ним отражающих горизонтов. Выделены: пачка D1op1 (соответствующие отражения D1opIV и Rngk); пачка D1op2 (отражение D1opIII); пачка D1op3 (отражение D1opII). Нумерация продуктивных пачек идет сверху вниз; названия отражающих горизонтов имеют стратиграфическую приуроченность.

За основу при разделении был принят стратиграфический разрез овинпармского горизонта, представленный в публикациях 3.П. Юрьевой и Йю. Валиукевичуса, основные реперные горизонты которого находят однозначное соответствие в полученном сейсмическом волновом поле (рис. 2).
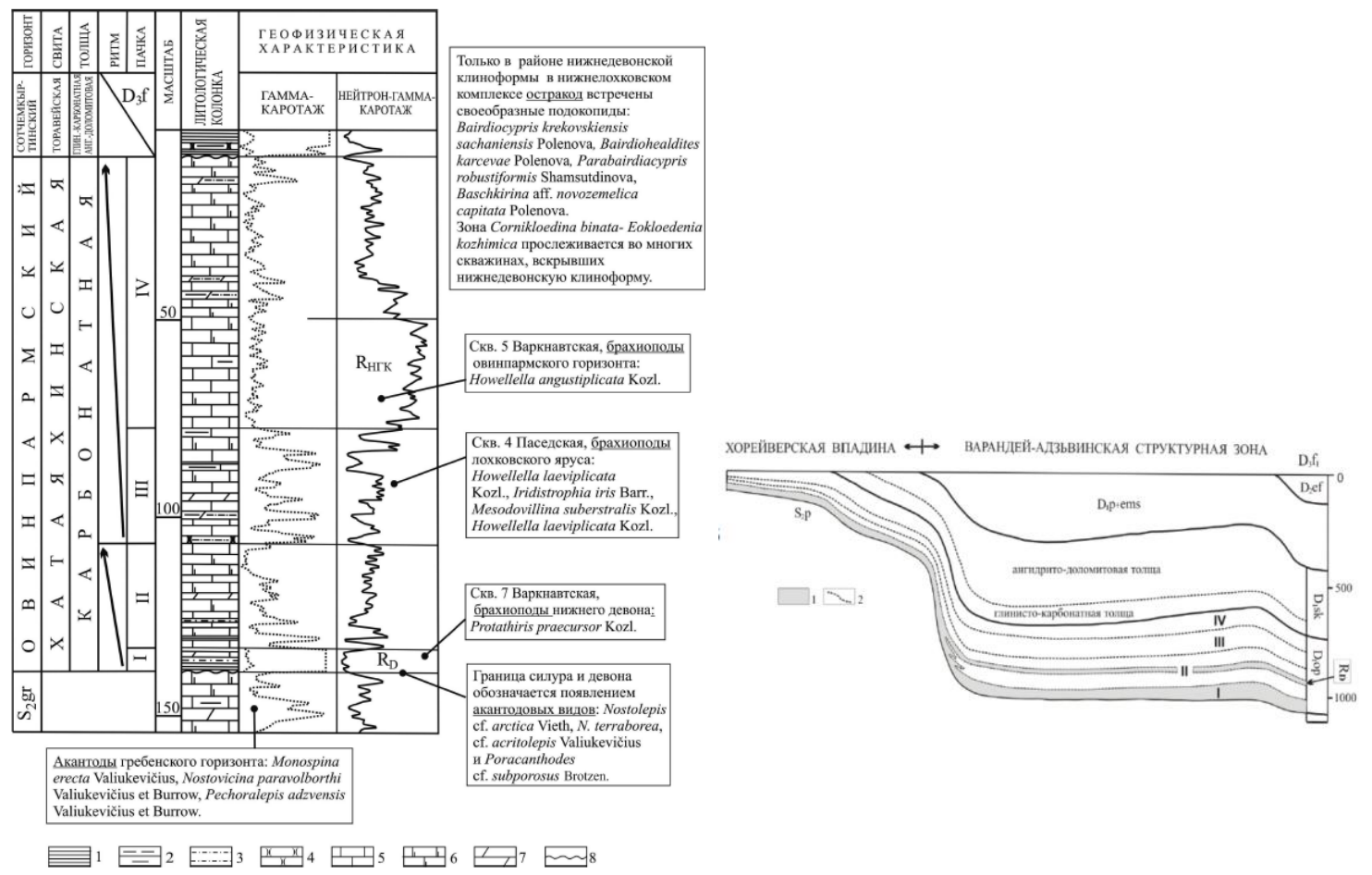

Рисунок 2 Стратиграфический разрез овинпармского горизонта восточной части

Хорейверской впадины (3. П. Юрьева, Йю. Валиукевичус, 2014 г.):

1 - аргиллиты, 2 - глинистость пород, 3 - алевролиты, 4 - песчаники, 5 - известняки,

6- доломиты вторичные, 7-мергели, 8-стратиграфическое несогласие

Глинистые отложения первой (базальной) пачки овинпармских отложений однозначно выделяются и в скважинных разрезах, и на сейсмических данных (сейсмо-гелогический репер). Им соответствует отражающий горизонт $\mathrm{Rd}$ (репер D), прослеживаемый, как интенсивное отрицательное отражение, практически по всей территории месторождения.

Второй опорной границей при интерпретации нижнедевонских отложений является отражение от поверхности предверхнедевонского размыва, имеющее на сейсмических разрезах вид однозначно определяемой положительной фазы с высокой амплитудой.

Два реперных отражения являются «каркасом», на основе которого проводится интерпретация остальных отражений. Достаточно выдержанная по площади мощность стратиграфических пачек II, III и IV и их закономерное срезание на западе под поверхность размыва позволяют проводить корреляцию горизонтов даже в зонах интерференции, где прослеживаемость затруднена. 
При этом хорошим подспорьем являются рассчитанные кубы относительного акустического импеданса: с импульсом, определенном в полосе частот амплитудного куба, и в более сглаженном виде, с частотами 10-30 Гц (рис. 3).
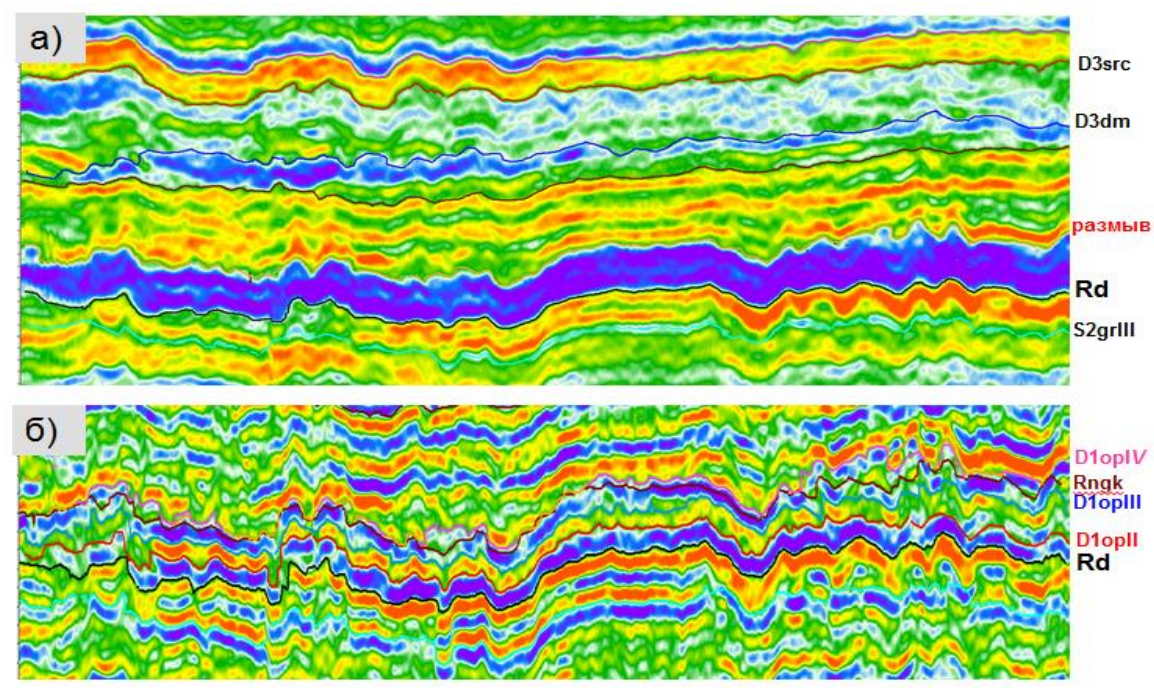

Рисунок. 3 Разрезы относительного акустического импеданса: а) низкочастотный; б) высокочастотный

Низкочастотный куб относительного акустического импеданса позволяет выявлять общие особенности распределения отложений различного возраста и определять положение кровли и подошвы овинпармских отложений. Для уточнения корреляции отражающих горизонтов внутри овинпармского интервала используется куб относительного акустического импеданса в более широкой полосе частот. Таким образом достигается высокая детальность выделения границ внутри интервала, что, в совокупности с учетом положения возможных разломных зон, является необходимым условием для определения мест успешного бурения скважин.

Основной продуктивной пачкой в отложениях овинпарма на месторождении им. P.Tребса является пачка D1opIV. На данный момент при интерпретации данных сейсморазведки критерием определения благоприятных зон является сохранность полной мощности отложений данной пачки. До получения последних сейсмических материалов сделать такой прогноз было практически невозможно, из-за недостаточно высокой разрешенности сейсмозаписи и неправильной интерпретации в зонах интерференции.

Специалистами ООО «БашНИПИнефть» используется простой критерий прогноза зон сохранности отложений пачки DlopIV: наличие устойчивого, хорошо выраженного отрицательного отражения, не затронутого явлениями некогерентности или интерференции. Очень важным условием при этом является выделение и отдельная корреляция отражения в нижней части пачки D1opIV, соответствующего кровле плотных карбонатов (известняки органогенно-детритовой структуры, неравномерно доломитизированные) - так называемому «реперу НГК» (Rngk). Интервал «репера НГК» в обязательном порядке должен быть изолирован от интервала оценки в пачке DlopIV. Граница его выхода под поверхность размыва также должна быть определена, чтобы избежать ошибок в определении мощности продуктивной пачки (рис. 4). 

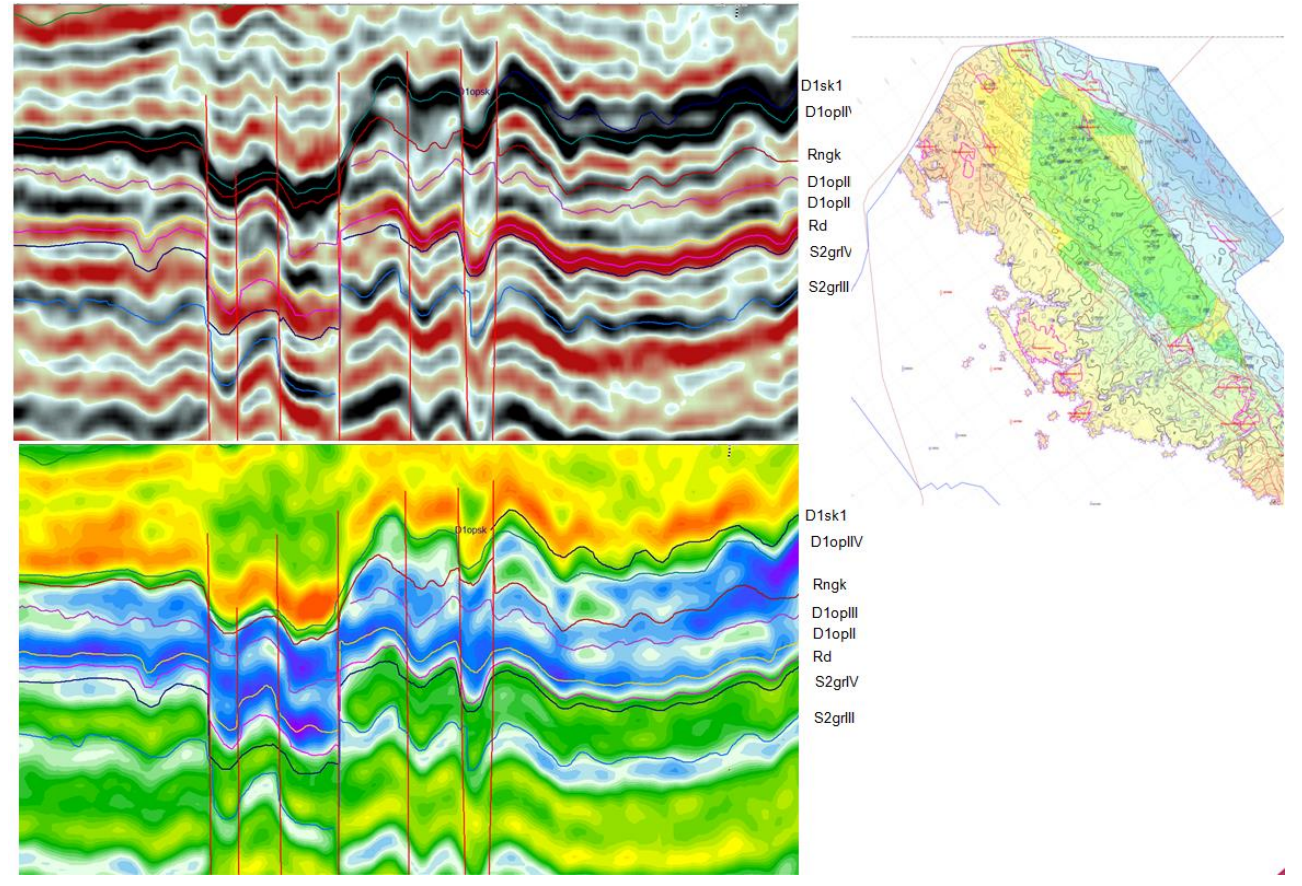

Рисунок 4 Временной разрез с выделеннм репером Rngk, выход его под размыв.

При выходе овинпармских пород под размыв на сейсмических данных наблюдается характерная особенность: формирование интерференционного эффекта (увеличения амплитуд отражения Rd) при наличии небольшой мощности перекрывающих отложений. Таким образом, имеется вполне реальная возможность определить, выходят ли под размыв отложения самой пачки (которые могут быть размыты), или выше нее будут встречены более молодые породы (тогда сохранность отложений изучаемой пачки под сомнение не ставится).

Рассмотренный подход к интерпретации данных сейсморазведки на месторождении им. Р.Требса используется при определении местоположения всех новых скважин. Статистическая оценка результатов бурения по 59 скважинам показывает его высокую эффективность, несмотря на предельную простоту. Первоначальный недоучет рекомендаций на перенос точек бурения привел к неудачным результатам в ряде скважин. При этом бурение на выданные рекомендации имеет практически полную подтверждаемость по наличию отложений продуктивной пачки.

Выводы: Специалистами ООО «БашНИПИнефть» разработан подход к определению зон уверенного наличия коллекторов в нижнедевонских отложениях на месторождении им. Р.Требса. Его основой является пофазная корреляция отражений от кровли каждой пачки, выделение кровли плотных карбонатов «репера НГК» и оценка интерференционного эффекта на границе размыва пород локховского яруса. Для проведения работы рассчитаны кубы имедансов в двух частотных диапазонах, позволяющие с высокой точностью определять границы выклинивания пачек и прогнозировать наличие полной мощности пород-коллекторов. Ранее подобная работа никем не проводилась. Внедрение подхода в практику свело к минимуму ошибки при заложении эксплуатационных скважин на месторождении им. Р.Требса. В настоящее время проводится его адаптация для применения на месторождении им А.Титова.

\section{Литература}

1. Куретова О.З., отчет «Сейсморазведочные работы МОГТ 2Д, ЗД на лицензионном участке, включающем месторождения им Р.Требса и им. А.Титова», 2015 г.

2. Митькина В.А. «Отчет по обобщению данных МОГТ-2Д прошлых лет с целью изучения строения осадочного чехла северо-восточной части Хорейверской впадины».

3. Юрьева 3.П., Валиукевичус Йю. «Нижнедевонская карбонатная клиноформа Хорейверской впадины Тимано-Североуральского региона (стратиграфия, корреляция)», 2014 г. 


\section{References}

1. "Seismic exploration work of MOGT 2D, 3D in the license area, including R.Trebs and A.Titov fields" report, O.Z. Kuretova, 2015.

2. "The report of previous years MOGT-2D data compilation to study the structure of the sedimentary cover of the north-eastern part of the Khoreyver depression", V.A. Mitkina.

3. "Lower Devonian carbonate clinoform of the Khoreyver depression in the TimanSeverouralsk region (stratigraphy, correlation)", Z.P.Yuryeva, Iu.Valiukevichus, 2014. 